\title{
Eating concerns, body dissatisfaction, thinness internalization and antifat attitudes and their relationship with gender ideology in a sample of men
}

\author{
Alejandro Magallares \\ Spanish Open University (UNED). Social Psychology Department. Madrid (Spain).
}

\begin{abstract}
Título: Preocupación por la comida, insatisfacción corporal, interiorización de la delgadez y actitudes antiobesos en su relación con las ideologías de género en una muestra de hombres.

Resumen: Los trastornos de la conducta alimentaria son mucho menos frecuentes en hombres que en mujeres. En este artículo se argumenta que esas diferencias pueden ser explicadas por las ideologías de género que tienen hombres y mujeres. La literatura sugiere que las mujeres interiorizan la normal social de delgadez y por esa razón acaban desarrollando preocupación por la comida e insatisfacción corporal con el paso del tiempo, mientras que los hombres externalizan el valor de la delgadez y es por ello que muestran más actitudes antiobesos que las mujeres. Los datos obtenidos de 450 estudiantes varones muestran que los participantes que puntuaban alto en ideología de género informaban de mayores actitudes antiobesos y menos interiorización de la delgadez, preocupación por la comida e insatisfacción corporal. Finalmente se discute porque los hombres y las mujeres adoptan diferentes estrategias para lidiar con la normal social de delgadez.

Palabras clave: ideología de género; preocupación por la comida, insatisfacción corporal, interiorización de la delgadez, actitudes antiobesos.
\end{abstract}

\section{Introduction}

Prevalence studies reveal that eating disorders are frequently found among young women and are much less common in men (Hudson, Hiripi, Pope, \& Kessler, 2007). According to some authors, these results may be partially explained by the individual differences that exist in the endorsement of gender ideologies (Swami \& Abbasnejad, 2010). Unfortunately, little research has explored the impact of gender ideology in men in their relationship with variables associated with eating disorders, such as eating concerns, body dissatisfaction or thinness internalization, as in the case of women (Swami \& Abbasnejad, 2010). Therefore, the current study attempts to test if the differences in the endorsement of the male ideology help to explain why men report less eating problems than women.

\section{Gender ideologies}

In Western cultures there is a great emphasis on physical appearance as a determinant of people's personal value (Thompson, Heinberg, Altabe, \& Tantleff-Dunn 1999). According to these authors, the female sociocultural beauty ideal is ultra-thin and both unattainable and unhealthy, while the male beauty ideal is related with a muscular body.

This cultural ideal of physical appearance is modeled through the mass media and repeated exposure to media images contributes to the internalization of these beauty

* Dirección para correspondencia [Correspondence address]:

Alejandro Magallares. UNED. School of Psychology. C/ Juan del Rosal, 10. 28040 Madrid (Spain). E-mail: amagallares@psi.uned.es

\begin{abstract}
Eating disorders are much less common in men than in women. In this paper it is argued that these differences may be explained by the gender ideology that men and women have. Literature suggests that women's ideology internalizes the social norm of slimness and for that reason may develop eating concerns and body dissatisfaction with the pass of the time, while men externalize the value of thinness and that is why they show greater antifat attitudes than women. Data obtained from 450 male students revealed that participants high in a gender ideology scale reported greater antifat attitudes and less thinness internalization, eating concerns and body dissatisfaction. Finally, it is discussed why men and women adopt different strategies to deal with the social norm of thinness.

Key words: gender ideology; eating concerns; body dissatisfaction; thinness externalization; antifat attitudes.
\end{abstract}

standards (Levine \& Murnen 2009). According to the reviewed literature, Western society promotes an appearance culture for both males and females, although dieting and a drive for thinness are more typical of female concerns (McKinley, 2006) because a key attribute of female beauty is a low body weight (Stice \& Shaw, 2002). In contrast, instead of low weight, many men in industrialized countries desire a larger body, with more muscle, which is consistent with the male gender ideology (Bottamini, 2006).

Gender role norms are socially constructed expectations about behavior and traits considered appropriate for men and women in a specific culture (Pleck, Sonenstein, \& Ku, 1993) and gender ideology is the individual internalization of these gender role norms (Pleck et al., 1993). The internalization of this set of social and behavioral norms that are generally considered appropriate for men and women also refers to the way that men and women should look.

In the case of the appearance component of gender ideologies for men and women, there is evidence about that these Western cultural values and ideals of beauty, that the mass media help to disseminate and some individuals internalize, have a major role in explaining why people may develop eating disorders (Jimenez-Cruz \& Silva-Gutierrez, 2010). As a matter of fact, it has been showed that mass media exposure to this beauty standard is related with the apparition of body image problems and eating concerns in both men (for a meta-analysis see: Barlett, Vowels, \& Edman, 2008) and women (for a meta-analysis see: Groesz, Levine, \& Murnen, 2002), which are both important predictors of eating disorders (Cohen \& Petrie, 2005). 
The internalization of these appearance ideals has important effects for women as several studies have showed. For example, previous studies have showed that gender ideology is related to body dissatisfaction (for a meta-analysis see: Murnen \& Smolak, 2009) and eating concerns (for a meta-analysis see: Murnen \& Smolak, 1997) in women. These studies assess the degree to which participants endorse traditional femininity ideology and how these scores in gender ideology scales are related to eating concerns and body image problems. In the same line, other investigations have showed, in this case with experimental designs, that exposure to non-traditional women ideology, such as feminists, may improve the body satisfaction of the participants (Peterson, Tantleff-Dunn, \& Bedwell, 2006). These results suggest that the endorsement of feminist ideologies (vs traditional female ideologies) may prevent the apparition of body dissatisfaction and eating concerns in women. However, to the date there are not many studies analyzing if the male ideology may be working as a protective factor that helps males to develop less body dissatisfaction and eating concerns compared to women (Andersen, 1995).

Although there are not many studies about the relationship between male ideology and eating disorders, some results have showed that males with higher level of body dissatisfaction have also lower masculinity scores (Hosper \& Jansen, 2005), that masculine men are less worried about food choice and a healthy lifestyle (Levi, Chan, \& Pence, 2006), that male with eating disorders have less body image concern than women (Nuñez et al., 2012) and that masculinity has been associated with lower levels of eating concerns (Meyer, Blissett, \& Oldfield, 2001) which implies that femininity can be considered a risk factor to develop eating disorders and masculinity a protective factor (Hospers \& Jansen, 2005). For this reason, in this paper it is suggested that the differences in the endorsement of the male ideology may be explaining why men are less worried about their own weight and show higher body satisfaction than women (Morgan, 2012). According to what has been found with women, it would be expected that men with high scores in a male ideology scale should report less eating concerns and body dissatisfaction (Levant \& Richmond, 2007).

\section{Internalization-externalization hypothesis}

One of the explanations given for these gender differences in eating concerns and body dissatisfaction in men and women was advanced by Levine and Murnen (2009). According to these authors, the differences in gender ideologies in men and women are especially relevant in the case of the value of slimness, as it has been said before in this section (McFarland \& Petrie, 2012). The literature finds that thinness internalization, the extent to which a person accepts social ideals of beauty and slimness in order to achieve success and happiness in life, is more important for women than for men, which may explain why men have less eating concerns and body dissatisfaction than women (Morgan,
2012). In other words, the female ideology is linked to thinness internalization because the feminine role orientation in Western cultures is more focused on weight loss compared to men (Agras, Bryson, Hammer, \& Kraemer, 2007). As a matter of fact, an abundance of correlational and experimental research shows that exposure to muscular media figures, but not ultra thin models as in the case of women, contributes to men's body dissatisfaction (for a review see: Blond, 2008). In other words, muscular figures, but not thin bodies as in the case of women, make men feel bad, because by comparison, their own bodies seem small (Young, Gabriel, \& Hollar, 2013). According to these results, it would be expected that if women who endorse the female ideology about slimness have more eating concerns and body dissatisfaction, men who internalize the male social norm about appearance, less focused on weight loss, should be less worried about gaining weight. In other words, it is expected that males that score high in a male ideology scale should report less thinness internalization.

In the same lime, other works (Aruguete, Yates, \& Edman, 2006) suggest that women internalize the value of slimness while men, in contrast, externalize it. As stated by Aruguete et al. (2006): "women internalize the value of thinness $(. .$.$) and have a tendency to focus on their own bodies$ and thus become fearful of becoming fat, a pattern that results in body dissatisfaction. Men, in contrast, externalize the value of thinness. Unlike women, men focus on other people's bodies and consequently show dislike of fat people" (pag. 186-187). According to these authors, women tend to focus on their own weight and body and therefore to become fearful of developing weight problems, while men pay attention to slimness in other's bodies to appreciate it or to criticize it, as in the case of obese people. In other words, men judge bodies and women are judged by their bodies (Wiederman, 2005). As a matter of fact, it has been found that men report greater antifat attitudes than women (Crandall, 1994). Other works show that men report less body dissatisfaction (Bully \& Elosua, 2011) and eating concerns (Meyer, McPartlan, Rawlinson, Bunting, \& Waller, 2011) than women. Additionally, there are studies that reveal that there is a link between ideology, like Right Wing Authoritarianism, Believe in a Just World or Modern Racism, and antifat attitudes (Crandall, 1994), and between gender related ideologies and antifat attitudes (Perez, Lewis, \& Cash, 2001) which suggests that gender male ideologies may be related to thinness externalization although there are not studies analyzing it so far. In other words, the studies reviewed have found that men are less worried about gaining weight because they externalize the value of thinness and for that reason they are less tolerant with people with weight problems, which suggests that males that endorse the male ideology about appearance should also report greater prejudices toward obese people (Magallares \& Morales, 2013). As it has been pointed out, there are few investigations about the internalization/externalization hypotheses, but according to the studies conducted so far it seems that men focus more 
on the weight of others than women that are more worried of gaining weight. For this reason, it is expected that men with high scores in a male ideology scale should report greater antifat attitudes.

Therefore, the main purpose of the current study is to describe the relationship that exists between gender male ideology and some variables like eating concerns, body dissatisfaction, thinness internalization and antifat attitudes in men in a cross-sectional study. Eating concerns and body dissatisfaction are measured because the investigation that has been done so far has showed that they are related with the apparition of eating disorders and this work may allow to a better understanding of the epidemiology of eating disorders in men and women (Neumark-Sztainer, Wall, Story, \& Sherwood, 2009). Additionally, the aim of this paper is also to analyze if the internalization-externalization hypothesis may be applied in a sample of male university students.

The prediction, based on previous studies, is that, on the first place, men with high scores in a male ideology scale, measured with the Male-Female Relations Questionnaire, will report less eating concerns, measured with the Eating Attitudes Test, than participants with low scores (first hypothesis) (Meyer, Blissett, \& Oldfield, 2001). On the second place, it is expected that men with high scores in a male ideology scale will show less body dissatisfaction, measured with the Body Shape Questionnaire, than participants with low scores (second hypothesis) (Hosper \& Jansen, 2005). On the third place, men with high scores on a male ideology scale will report less thinness internalization, measured with the Attitudes Towards Appearance Questionnaire, than participants with low scores (third hypothesis) (Aruguete et al., 2006). And finally, men with high scores on a male ideology scale will report more antifat attitudes, measured with the Antifat Attitudes Questionnaire, than males who score low in the male ideology scale (fourth hypothesis) (Crandall, 1994).

\section{Method}

\section{Sample}

Participants were 450 Spanish male students of the UNED (Spanish Open University) from 18 to 29 years (age: Mean $=24.68, S D=3.32$ ) who were enrolled in a psychology course and who received extra credit for their participation. All participants were normal weight (Body Mass Index or BMI between 18 and 25; Mean $=21.21, S D=1.87$ ).

\section{Procedure}

To recruit participants, students of all the Spanish territory were contacted trough the webpage of the university. Students were informed on the general purposes of the research and those who voluntarily wanted to participate filled out a booklet with the different questionnaires that was available for a short period of time in the webpage to be downloaded. After completing all the scales, participants deliver their answers by post to the main researcher.

Participants who had more than 29 years and had BMI lower than 18 (underweight) or higher to 25 (overweight) were excluded from the final analysis in order to make the sample the most homogenous possible.

\section{Instruments}

To measure male ideology it was used the subscale of Social Interaction of the Male-Female Relations Questionnaire (MFRQ) (Spence, Helmreich \& Sawin, 1980; Spanish Version: Castillo-Mayen, 2011) The MFRQ is a measure of sex-role behaviors and preferences. The Social Interaction subscale $(\alpha=.94)$ consists of 16 items scored on a 5 -point Likert scale ranging from "strongly disagree" (1) to "strongly agree" (5). A score was computed by averaging the 16 items of the subscale of the MFRQ. Higher scores on the Social Interactions subscale of the MFRQ reflect greater tendency to conform to traditional sex-role pressures. An example of this scale is "I'd rather have a man as a boss at work than a woman".

To measure if participants had eating concerns and body dissatisfaction it was used the Spanish versions of the Eating Attitudes Test (EAT-26) (English version: Garner and Garfinkel, 1979; Garner et al, 1982; Spanish version: Rivas, Bersabé, Jiménez, \& Berrocal, 2010) and the Body Shape Questionnaire (BSQ) (Cooper, Taylor, Cooper \& Fairburn, 1987; Spanish version: Raich et al., 1996). The EAT-26 ( $\alpha=$ .86) consists of 26 items scored on a 5-point Likert scale ranging from "never" (1) to "always" (5). A score was computed by averaging the 26 items of the scale. Higher scores on the EAT-26 reflect greater eating concerns. An example of this scale is "I am terrified about being overweight". The BSQ $(\alpha=.96)$ consists of 34 items scored on a 5 -point Likert scale ranging from "never" (1) to "always" (5). A score was computed by averaging the 34 items of the scale. Higher scores on the BSQ reflect greater concerns about body shape and body dissatisfaction (Stice \& Shaw, 2002), especially their concerns of feeling fat. An example of this scale is "Have you worried about your flesh being not firm enough?”

To measure thinness internalization the subscale of Internalization of the Sociocultural Attitudes Towards Appearance Questionnaire (SATAQ) was used (Heinberg, Thompson \& Stormer, 1995; Spanish version: Llorente, Warren, de Eulate, \& Gleaves, 2013). This subscale of the SATAQ is a measure that assesses awareness of sociocultural pressures to be thin and attractive and internalization of those standards. The Internalization subscale of the SATAQ $(\alpha=.84)$ consists of 7 items on 5-point Likert-type scale ranging from strongly disagree (1) to strongly agree (5). A score was computed by averaging the 7 items of the subscale. Higher scores on the SATAQ subscale reflect greater thinness internalization. An example of this scale is "I've felt pressure from TV or magazines to lose weight." 
To measure anti-fat attitudes the subscale of dislike of the Antifat Attitudes Questionnaire (AFA) (Crandall, 1994; Spanish version: Magallares \& Morales, 2014) was used. The AFA evaluates attitudes toward overweight and obese individuals. The Dislike subscale of the AFA $(\alpha=.85)$ consists of 7 items scored on a 5 -point Likert scale ranging from "strongly disagree" (1) to "strongly agree" (5). A score was computed by averaging the 7 items of the subscale. Higher scores on the dislike subscale reflect greater negative attitudes toward obese people. An example of this scale is "I really don't like fat people much".

\section{Results}

First of all, descriptives for all the variables of the study were calculated as it can be seen in Table 1 .

Table 1. Descriptives of all the variables of the study $(\mathrm{N}=450)$.

\begin{tabular}{lccccc}
\hline & MFRQ & EAT-26 & BSQ & SATAQ & AFA \\
\hline$M$ & 3.02 & 1.86 & 1.77 & 2.42 & 1.96 \\
SD & .31 & .44 & .63 & .59 & .73
\end{tabular}

Notes: All scales from 1 to 5; MFRQ: Male Female Relations Questionnaire (male ideology); EAT-26 = Eating Attitudes Test (eating concerns); BSQ: Body Shape Questionnaire (body dissatisfaction); SATAQ: Sociocultural Attitudes Toward Appearance Questionnaire (thinness internalization); AFA: Antifat Attitudes

In order to analyze if men who endorse a strong male ideology (MFRQ) reported less eating concerns (EAT-26), body dissatisfaction (BSQ) and thinness internalization (SATAQ) and greater antifat attitudes (AFA) it was decided to select individuals with more extreme scores.

The groups of participants were formed by categorizing those individuals with the higher and lower scores on the male ideology scale (25\% upper and 25\% below). Participants with medium scores were not selected for the final sample and were excluded of the analysis.

According to previous criterion, 222 individuals were selected (low scores on the MFRQ: $\mathrm{n}=121$; and high scores on the MFRQ group: $n=101)$. These groups were correctly formed, given that the mean scores on the classification variable (MFRQ) were significantly different between groups [low score on MFRQ $=2.61, S D=.29$ vs high score on MFRQ $\left.=3.31, S D=.32 ; F_{1,220}=1087.01, p<.01\right]$. It was calculated a one way ANOVA with the extreme groups as a factor and the male ideology scale as a dependent variable to show that the groups were formed correctly. This procedure has been used before (Hinde \& Dennis, 1986) showing that it is useful to test differences between groups with extreme scores (Revelle, 2007).

Comparisons between these groups on all the variables (eating concerns, body dissatisfaction, thinness internalization and antifat attitudes) were made by means of the Multiple Analysis of Variance (MANOVA). Cohen's ds (Cohen, 1988) were also calculated as indexes of effect size. Cohen (1988) defined $d$ as the difference between means divided by standard deviation of either group ( $d s \geq .2$ are considered medium effect sizes and $d s \geq .8$ large effect sizes; Cohen, 1988).

A MANOVA was conducted (see Table 2), with the male ideology scale (MFRQ) as a factor (two groups: low and high scores) and EAT-26, BSQ, SATAQ and AFA as dependent variables in order to test the hypotheses. The MANOVA revealed a significant multivariate main effect for MFRQ [Wilks' $\left.\lambda=.76, F_{1,220}=20.47, p<.01\right]$.

The results showed that men with higher scores in MFRQ (male ideology) reported lower scores on the EAT26, and the BSQ (with medium effect sizes). Additionally, it was found that men high on MFRQ reported lower scores on the SATAQ and more AFA than the low score group (with high effect sizes). The differences were statistically significant (see Table 2).

Table 2. Differences between groups (MFRQ) on EAT-26, BSQ, SATAQ and AFA.

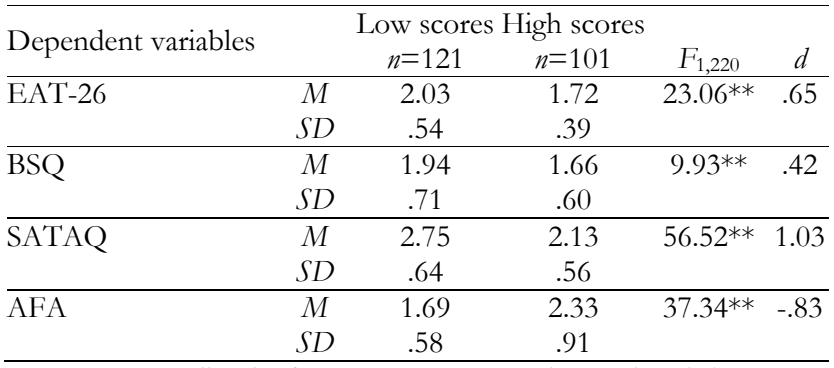

Notes: ${ }^{* *} p<.01$; All scales from 1 to 5; MFRQ: Male Female Relations Questionnaire (male ideology); EAT-26 = Eating Attitudes Test (eating concerns); BSQ: Body Shape Questionnaire (body dissatisfaction); SATAQ: Sociocultural Attitudes Toward Appearance Questionnaire (thinness internalization); AFA: Antifat Attitudes

\section{Conclusions}

Taken together, these results give support to the four hypotheses of the current research: men high in a male ideology scale report less eating concerns (first hypothesis), body dissatisfaction (second hypothesis), thinness internalization (third hypothesis) and more antifat attitudes (fourth hypothesis) than participants with low scores on a male ideology scale.

\section{Discussion}

According to the results, it appears that gender ideology plays a significant role in explaining why men report less eating concerns and body dissatisfaction than women (Andersen, 1995). Previous works had showed a relationship between traditional female ideology and less body satisfaction (Swami \& Abbasnejad, 2010), and other investigations had showed that women who endorse the female ideology reported more eating concerns (Murnen \& Smolak, 1997) but it was not found any study about the relationship between gender male ideology and these predictors of eating disorders (Neumark-Sztainer et al., 2009). In the current research, the relationship found for men is the opposite, 
because results show a negative link between the endorsement of a strong male ideology and body dissatisfaction and eating concerns. It is important to remark that this is the first time that it has been showed that male ideology is negatively related to the apparition of eating concerns and body dissatisfaction in a sample of men although this result is similar to other works that have found a negative relationship between masculinity and body dissatisfaction and eating problems (Hosper \& Jansen, 2005). Specifically, the obtained results show that men with a high score on a male ideology scale report less eating concerns and body dissatisfaction. These results suggest that the endorsement of a strong gender male ideology may work as a protective factor that helps men to have a higher body satisfaction and less eating concerns.

Other interesting result is that men high in a male ideology scale also report more antifat attitudes which is consistent with the works that have showed that negative attitudes toward obese people are linked with gender ideology variables (Perez et al., 2001). It is important to remark, that the effect size found is high which gives the idea of the strength of the relationship that exists between gender ideologies and the negative attitudes toward obese people.

The results of the current study give support the idea that men externalize the value of thinness (Aruguete et al., 2006), especially individuals that endorse with strength the male ideology. According to what it has been found, men high in a male ideology scale report less thinness internalization with a high effect size, it appears that in the case of men who internalize the traditional male role it is expected that they have to appreciate beauty and slimness in other bodies but they do not have the obligation to apply this standard to themselves. The differences in the internalization of the value of slimness found for males with high and low scores on a male ideology scale also helps to understand why studies reveal that men are more satisfied with their bodies and present less eating concerns than women (Andersen, 1995). Additionally, men who report low scores on a male ideology scale are at highest risk to develop problems related to eating disorders as other researchers suggest (Hosper \& Jansen, 2005).

In general, this pattern of results may be explained because, as it has been said, Westem sociocultural norms emphasize and idealize extreme slimness for women but not for men (Murnen, 2011). This current standard of femininity disproportionately associates women's worth with their bodies (Steinfeldt, Zakrajsek, Carter, \& Steinfeldt, 2011). Especially relevant is the role that mass media has on the dissem-

\section{References}

Agras, W., Bryson, S., Hammer, L., \& Kraemer, H. (2007). Childhood Risk Factors for Thin Body Preoccupation and Social Pressure to Be Thin. Journal of the American Academy of Child \& Adolescent Psychiatry, 46, 171178. doi: $10.1097 /$ chi.0b013e31802bd997

Andersen, A.E. (1995). Eating disorders in males. In K. D Brownell, C.G. Fairburn, (eds.), Eating disorders and Obesity: A Comprehensive Handbook (pp. 177-187). New York: The Guilford Press. ination of the message of extreme thinness in women (Bell \& Dittmar, 2011). For that reason, men, especially who have a strong male ideology, do not feel the same pressure to lose weight than women (Fernandez \& Pritchard, 2012). It is important to remark that thinness internalization is fostered by perceived pressure to be slim which is more important in women than in men. In other words, men are less likely to internalize the slimness ideal, and for that reason they report less eating concerns and body dissatisfaction than women, because they receive less pressuring messages in interactions with family and friends (Thompson et al., 1999).

As it has been said above, the results suggest that male ideology may work as a protective factor that helps men to avoid developing eating disorders. For this reason, interventions designed to improve the lives of young girls may include, in their programs to address eating disorders and body image concerns, interpersonal and social skills more related with male abilities to educate girls about the risks associated with eating disorders (Marco, Perpiña, \& Botella, 2014).

It is important to remark that in this work it has not been measured the drive for muscularity which in the case of men is an important part of the male gender ideology (McFarland, \& Petrie, 2012). According to the reviewed literature, although men who endorse the male ideology are less vulnerable to develop body dissatisfaction and eating concerns, as it has been saw in this paper, it should be expected that male individuals that score high in a male gender ideology scale may have greater drive for muscularity that those with low scores on these scales. Future research should include this type of measures in order to assess if men high in male ideology scales also report more drive for muscularity.

The current study is subject to some limitations that deserve mention. First of all, it should be noted that the sample consisted of psychology students and that it would be necessary to reply these findings with clinical samples in order to improve the quality of the study. Second, in the research self-reports has been used. It would be necessary, for future investigations, to conduct studies with the same goals, using not only self-reports, but also more objective criteria, evaluating the same constructs with alternative measures (Richetin, Xaiz, Maravita, \& Perugini, 2012). Finally, it is a cross-sectional study. However, only longitudinal studies can provide insight into how the variables studied in this paper interact with different daily life stressful experiences. Despite these limitations, the study provides new data with potential applications.

Aruguete, M., Yates, A., \& Edman, J. (2006). Gender Differences in Attitudes about Fat. North American Journal of Psychology, 8, 183-192.

Barlett, C. P., Vowels, C. L., \& Saucier, D. A. (2008). Meta-analyses of the effects of media images on men's body-image concerns. Journal of Social and Clinical Psychology, 27, 279 -310. doi: 10.1521/jscp.2008.27.3.279

Bell, B. \& Dittmar, H. (2011). Does Media Type Matter? The Role of Identification in Adolescent Girls' Media Consumption and the Impact of 
Different Thin-Ideal Mediaon Body Image. Sex Roles, 65, 478-490. doi: 10.1007/s11199-011-9964-x.

Blond, A. (2008). Impacts of exposure to images of ideal bodies on male body dissatisfaction: A review. Body Image, 5, 244-250. doi: 10.1016/j.bodyim.2008.02.003

Bottamini, G. (2006). Male voices on body image. International Journal of Men's Health, 5, 109-132. doi: 10.3149/jmh.0502.109

Bully, P. \& Elosua, P. (2011). Changes in body dissatisfaction relative to gender and age: The modulating character of BMI. The Spanish Journal of Psychology, 14, 313-322. doi: 10.5209/rev SJOP.2011.v14.n1.28

Castillo-Mayén, M. R. (2011). Orientación a la dominancia social e identidad de género: mediación de variables socializadoras del género/Social dominance orientation and gender identity]. Jaén: Servicio de Publicaciones de la Universidad de Jaén.

Cohen, J. (1988). Statistical power analysis for the behavior sciences. New York: Lawrence Earlbaum Associates.

Cohen, D. \& Petrie, T. (2005). An Examination of Psychosocial Correlates of Disordered Eating among Undergraduate Women. Sex Roles, 52, 2942. doi: $10.1007 / \mathrm{s} 11199-005-1191-\mathrm{x}$

Cooper, P.J., M.J. Taylor, Z. Cooper, \& C.G. Fairburn (1987). The development and validation of the Body Shape Questionnaire. International Journal of Eating Disorders, 6, 485-494. doi: 10.1002/1098108X(198707)6:4<485::AID-EAT2260060405>3.0.CO;2-O

Crandall, C.S. (1994). Prejudice Against Fat People: Ideology and SelfInterest. Journal of Personality and Social Psychology, 66, 882-894. doi: 10.1037//0022-3514.66.5.882

Fernandez, S. \& Pritchard, M. (2012). Relationships between self-esteem, media influence and drive for thinness. Eating Behaviors, 13, 321-325. doi: 10.1016/i.eatbeh.2012.05.004

Garner, D.M \& Garfinkel, P.E. (1979). The eating attitudes test: An index of the symptoms of anorexia nervosa. Psychological Medicine, 9, 273-279. doi: $10.1017 / \mathrm{S} 0033291700030762$

Garner, D.M., Olmsted, M.P., Bohr, Y., \& Garfinkel, P.E. (1982). The Eating Attitudes Test: Psychometric features and clinical correlates. Psychological Medicine, 12, 871-878. doi: 10.1017/S0033291700049163

Groesz, L. M., Levine, M. P., \& Murnen, S. K. (2002). The effect of experimental presentation of thin media images on body satisfaction: A metaanalytic review. International Journal of Eating Disorders, 31, 1-16. doi:10.1002/eat.10005

Heinberg, L.,Thompson, K. \& Stormer, S. (1995). Development and Validation of the Sociocultural Attitudes Towards Appearance Questionnaire. International Journal of Eating Disorders, 17, 81-89. doi: 10.1002/1098108X(199501)17:1<81::AID-EAT2260170111>3.0.CO;2-Y

Hinde, R. \& Dennis, A. (1986). Categorizing Individuals: An Alternative to Linear Analysis. International Journal of Behavioral Development, 9, 105 -119. doi: 10.1177/016502548600900107

Hospers, J. \& Jansen, A. (2005). Why homosexuality is a risk factor for eating disorders in males. Journal of Social \& Clinical Psychology, 24, 1188-1201. doi: $10.1521 /$ iscp. 2005.24.8.1188

Hudson, J.I., Hiripi, E., Pope, H.G. \& Kessler, R.C. (2007). The prevalence and correlates of eating disorders in the National Comorbidity Survey Replication. Biological psychiatry, 61, 348-358. doi: 10.1016/i.biopsych.2006.03.040

Jimenez-Cruz, B.E. \& Silva-Gutierrez, C. (2010). Riesgo para trastorno alimentario, ansiedad, depresión y otras emociones asociadas a la exposición de imágenes publicitarias [Risk for eating disorders, anxiety, depression and other emotions related to publicitary images exposure]. Anales de psicología, 26, 11-17. doi:10.6018/91911

Levant, R. \& Richmond, K. (2007). A Review of Research on Masculinity Ideologies Using the Male Role Norms Inventory. The Journal of Men's Studies, 15, 130-146. doi: 10.3149/jms.1502.130

Levi, A., Chan, K., \& Pence, D. (2006). Real Men Do Not Read Labels: The Effects of Masculinity and Involvement on College Students' Food Decisions. Journal of American College Health, 55, 91-98. doi:10.3200/JACH.55.2.91-98

Levine, M. P. \& Murnen, S. (2009). "Everybody knows that mass media [pick one] are not a cause of eating disorders": A critical review of evidence for a causal link between media, negative body image, and disordered eating in females. Journal of Clinical and Social Psychology, 28, 9-42. doi: $10.1521 /$ iscp.2009.28.1.9
Llorente, E., Warren, C.S., de Eulate, L.P., \& Gleaves, D.H. (2013). A Spanish version of the Sociocultural Attitudes Towards Appearance Questionnaire-3 (SATAQ-3): translation and psychometric evaluation. Journal of Clinical Psychology, 69, 240-251. doi: 10.1002/jclp.21944

Magallares, A. \& Morales, J.F. (2013). Gender differences in antifat attitudes. Revista de Psicologia Social, 28, 113-119. doi: 10.1174/021347413804756014

Magallares, A. \& Morales, J.F. (2014). Adaptación al castellano de la Escala de Actitud Antiobesos [Spanish adaptation of the Antifat Attitudes Scale]. Revista de Psicologia Social, 29. doi: 10.1080/02134748.2014.972707

Marco, J.H., Perpiña, C., \& Botella, C. (2014). Tratamiento de la imagen corporal en los trastornos alimentarios y cambio clínicamente significativo [The treatment of the body image disturbances in eating disorders and clinically significant change]. Anales de psicología, 30, 422-430. doi: 10.6018/analesps.30.2.151291

McFarland, M. \& Petrie, T. (2012). Male body satisfaction: Factorial and construct validity of the Body Parts Satisfaction Scale for men. Journal of Counseling Psychology, 59, 329-337. doi:10.1037/a0026777

McKinley, N. (2006). Longitudinal Gender Differences in Objectified Body Consciousness and Weight-Related Attitudes and Behaviors: Cultural and Developmental Contexts in the Transition from College. Sex Roles, 54, 159-173. DOI: $10.1007 / \mathrm{s} 11199-006-9335-1$.

Meyer, C., Blissett, J., \& Oldfield, C. (2001). Sexual orientation and eating psychopathology: The role of masculinity and femininity. International Journal of Eating Disorders, 29, 314-318. doi: 10.1002/eat.1024

Meyer, C., McPartlan, L., Rawlinson, A., Bunting, J., \& Waller, G. (2011) Related Behaviours and Cognitions: Relationship to Eating Psychopathology in Non-Clinical Women and Men. Behavioural \& Cognitive Psychotherapy, 39, 591-600. doi: 10.1017/S1352465811000270

Morgan, J. (2012). Male eating disorders. In A. June \& J.Treasure (eds.), A collaborative approach to eating disorders (pp. 272-278). New York: Taylor \& Francis Group.

Murnen, S. (2011). Gender and body images. In T. Cash \& L. Smolak (Eds.), Body image: A handbook of science, practice, and prevention (pp. 173-179). New York: Guilford Press. doi: 10.1016/B978-0-12-384925-0.00019-5

Murnen, S. K., \& Smolak, L. (1997). Femininity, masculinity, and disordered eating: A meta-analytic review. International Journal of Eating Disorders, 22, 231-242. doi: 10.1002/(SICI) 1098-108X(199711)22:3<231::AIDEAT2>3.0.CO;2-O

Murnen, S. K., \& Smolak, L. (2009). Are Feminist Women Protected from Body Image Problems? A Meta-analytic Review of Relevant Research. Sex Roles, 60, 186-197. doi: 10.1007/s11199-008-9523-2

Neumark-Sztainer, D., Wall, M., Story, M., \& Sherwood, N. (2009). Fiveyear longitudinal predictive factors for disordered eating in a population-based sample of overweight adolescents: Implications for prevention and treatment. International Journal of Eating Disorders, 42, 664-672. doi: 10.1002/eat.20733.

Nuñez, A, Agüera Z., Krug, I., Jimenez, S., Sanchez, I., ... \& Fernandez, F. (2012). Do men with eating disorders differ from women in clinics, psychopathology and personality? European Eating Disorders Review, 20 , 23-31. doi: 10.1002/erv.1146

Perez, M., Lewis, R., \& Cash, T. (2001). The Relationship of Antifat Attitudes to Other Prejudicial and Gender-Related Attitudes. Journal of Applied Social Psychology, 31, 683-697. doi: 10.1111/j.15591816.2001.tb01408.x

Peterson, R., Tantleff-Dunn, S., \& Bedwell, J. (2006). The effects of exposure to feminist ideology on women's body image. Body Image, 3, $237-$ 246. doi: 10.1016/j.bodyim.2006.05.004

Pleck, J. H., Sonenstein, F. L., \& Ku, L. C. (1993). Masculinity ideology: Its impact on adolescent males' heterosexual relationships. Journal of Social Issues, 49, 11-29. doi: 10.1111/i.1540-4560.1993.tb01166.x

Presnell, K., Bearman, S., \& Stice, E. (2004). Risk factors for body dissatisfaction in adolescent boys and girls: a prospective study. International Journal of Eating Disorders, 36, 389-401. doi: 10.1002/eat.20045

Raich, R.M., Mora, M., Soler, A., Avila, C., Clos, I., \& Zapater L. (1996). Adaptación de un instrumento de evaluación de la insatisfacción corporal[Adaptation of a body dissatisfaction assessment instrument]. Clinica y Salud, 7, 51-66. 
Revelle, W. (2007). Experimental Approaches to the Study of Personality. In B. Robins, C. Fraley \& R. Krueger, Personality Research Methods (pp. $37-$ 61.). New York: Guilford.

Richetin, J., Xaiz, A., Maravita, A., \& Perugini, M. (2012). Self-body recognition depends on implicit self-esteem. Body Image, 9, 253-260. doi:10.1016/j.bodyim.2011.11.002

Rivas, T., Bersabé, R., Jiménez, M. \& Berrocal, C. (2010). The Eating Attitudes Test (EAT-26): Reliability and Validity in Spanish Female Samples. The Spanish Journal of Psychology, 13, 1044-1056. doi: $10.1017 /$ S1138741600002687

Spence, J.T., Helmreich, R. L., \& Sawin, L.L. (1980). The Male-Female Relations Questionnaire: A self-report inventory of sex-role behaviors and preferences and its relationships to masculine and femenine personality traits, sex-role attitudes and other measures. JS AS Catalog of $S_{e-}$ lected Documents in Psychology, 10,1-3.

Steinfeldt, J., Zakrajsek, R., Carter, H., \& Steinfeldt, M. (2011). Conformity to gender norms among female student-athletes: Implications for body image. Psychology of Men \& Masculinity, 12, 401-416. doi: $10.1037 / \mathrm{a} 0023634$
Stice E. \& Shaw, H.E. (2002). Role of body dissatisfaction in the onset and maintenance of eating pathology.Asynthesis of research findings. Journal of Psychosomatic Research, 53, 985-993. doi: 10.1016/S00223999(02)00488-9

Swami, V. \& Abbasnejad, A. (2010). Associations between femininity ideology and body appreciation among British female undergraduates. Personality and Individual Differences, 48, 685-687. doi: 10.1016/i.paid.2009.12.017

Thompson, J. K., Heinberg, L. J., Altabe, M. N., \& Tantleff-Dunn, S. (1999). Exacting beauty: Theory, assessment and treatment of body image disturbance. Washington: American Psychological Association. doi: $10.1037 / 10312-000$

Wiederman, M. (2005). The Gendered Nature of Sexual Scripts. The Family Journal, 13, 496-502.

Young, A., Gabriel, S. \& Hollar, J. (2013). Batman to the rescue! The protective effects of parasocial relationships with muscular superheroes on men's body image. Journal of Experimental Social Psychology, 49, 173-177. doi: 10.1016/j.jesp.2012.08.003

(Article received: 18-09-2013; revised: 26-10-2014; accepted: 19-11-2014) 